\title{
Advances in COVID-19 research
}

until November 2020: Update from the UNCOVER registry

\section{Xiaomeng Zhang ${ }^{1 *}$, Wei $\mathrm{Xu}^{1 *}$, Marshall Dozier ${ }^{2}$, Farirai P Nzvere ${ }^{1}$, Prerna Krishan ${ }^{1}$, Yazhou He ${ }^{1,3}$, Xue $\mathrm{Li}^{4,5}$, Evropi Theodoratou ${ }^{1,6}$; on behalf of UNCOVER}

\author{
${ }^{1}$ Centre for Global Health, Usher Institute, University of Edinburgh, Edinburgh, UK \\ ${ }^{2}$ Information Services, University of Edinburgh, Edinburgh, UK \\ ${ }^{3}$ West China School of Public Health and West China Fourth Hospital, Sichuan University, Chengdu, PR China \\ ${ }^{4}$ School of Public Health, Zhejiang University, Hangzhou, PR China \\ ${ }^{5}$ Second Affiliated Hospital, Zhejiang University, Hangzhou, PR China \\ ${ }^{6}$ Cancer Research UK Edinburgh Centre, Medical Research Council Institute of Genetics and Molecular Medicine, University of Edin- \\ burgh, Edinburgh, UK \\ * Joint first authorship.
}

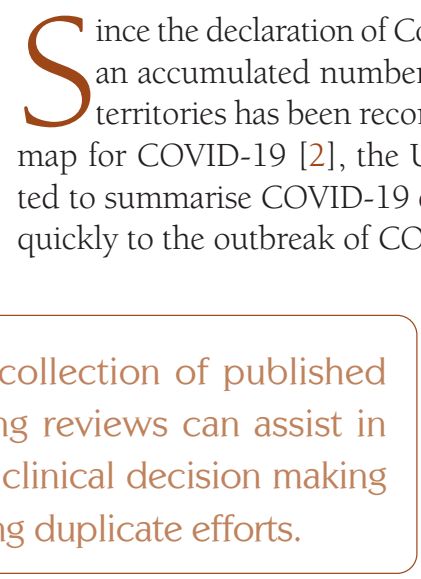

\section{An online collection of published and ongoing reviews can assist in policy and clinical decision making and avoiding duplicate efforts.}

134 protocols (Figure 1, Panel A) [4]. The website has been accessed a total of 9094 times with 4169 times abstract viewing and 3150 times completed review viewing. The publication sources for COVID-19 evidencebased reviews in the UNCOVER register include PubMed $(n=1450)$, WHO COVID-19 database $(n=384)$, medRxiv ( $n=408)$, and other websites $(n=92)$ such as the national collaborating centre for methods and tools [5] and The Centre for Evidence-Based Medicine [6] (Figure 1, Panel B).

Research topics of indexed reviews were categorised thematically according to McMaster University COVIDEND (COVID-19 Evidence Network to support Decision-making) taxonomy into five groups: 1) Clinical management of COVID-19 and pandemic-related health issues ( $\mathrm{n}=1755,75.2 \%)$; 2 ) Public-health measures 
A

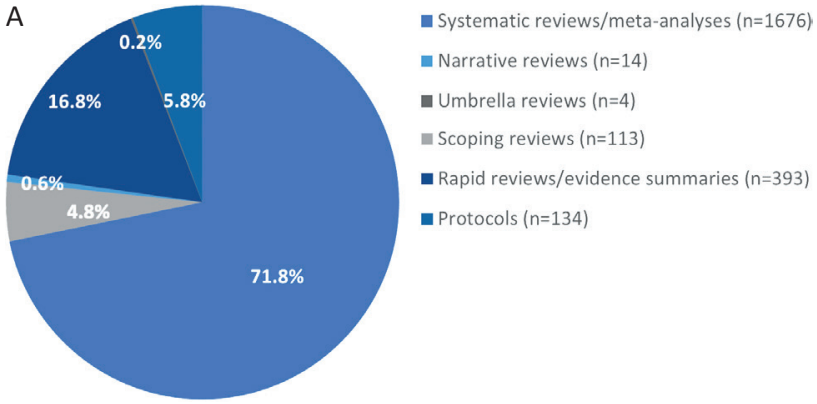

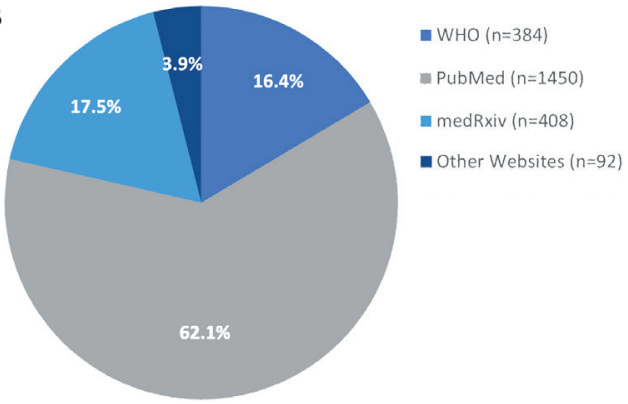

Figure 1. Review types and review sources of the included reviews in the UNCOVER registry. Panel A. Review types. Panel B. Review sources. medRxiv preprints were replaced with the peer-reviewed publications once they have been published in peer-reviewed journals; the review types displayed directly in the searching results of the website and the review sources can be accessed through the filter.

( $n=342,14.7 \%) ; 3$ ) Health-system arrangements $(n=85,3.6 \%) ; 4)$ Economic and social responses $(n=59$, $2.5 \%) ; 5$ ) Other reviews ( $n=93,4.0 \%$ ) (Figure 2, Panel A) [7]. We further categorised each review into 22 subgroups under the five COVIDEND groups (Table 1):

Table 1. Categories and selected sub-categories of research topics of reviews included in the UNCOVER registry.

\begin{tabular}{|c|c|c|c|c|}
\hline $\begin{array}{l}\text { CLINICAL MANAGEMENT OF } \\
\text { COVID- } 19 \text { AND PANDEMIC- } \\
\text { RELATED HEALTH ISSUES } \\
(\mathrm{N}=1755)\end{array}$ & $\begin{array}{l}\text { PUBLIC-HEALTH MEASURES } \\
(\mathrm{N}=342)\end{array}$ & $\begin{array}{l}\text { HEALTH-SYSTEM } \\
\text { ARRANGEMENTS( }=85)\end{array}$ & $\begin{array}{l}\text { ECONOMIC AND SOCIAL } \\
\text { RESPONSES ( } N=59 \text { ) }\end{array}$ & OTHER REVIEWS(N = 93) \\
\hline Clinical features $(n=372)$ & Infection $(\mathrm{n}=37)$ & $\begin{array}{l}\text { Health care resource } \\
\text { arrangement }(n=38)\end{array}$ & Education $(n=11)$ & $\begin{array}{l}\text { Comparison of COVID-19, } \\
\text { SARS, and MERS }(n=32)\end{array}$ \\
\hline - Symptoms & - Infection route & $\begin{array}{l}\text { - Allocation of ICU beds } \\
\text { and ventilators }\end{array}$ & - Public health education & - Viral load dynamics \\
\hline - Biochemical indicators & - Secondary infection & - Primary health care & Social consequences $(n=29)$ & - Duration of viral shedding \\
\hline Clinical tests $(n=147)$ & Transmission $(n=115)$ & - Orthodontic care & - Bereavement & Published articles $(\mathrm{n}=25)$ \\
\hline $\begin{array}{l}\text { - Effectiveness of diagnostic } \\
\text { test }\end{array}$ & - Transmission route & - Neurosurgical practice & - Domestic violence & $\begin{array}{l}\text { - Methodological quality of } \\
\text { COVID-19 systematic reviews }\end{array}$ \\
\hline - CT imaging and findings & - R number & $\begin{array}{l}\text { Clinical departments } \\
\text { arrangement }(n=42)\end{array}$ & Economy $(\mathrm{n}=7)$ & $\begin{array}{l}\text { Coronavirus genomic RNA } \\
\text { packaging }(\mathrm{n}=19)\end{array}$ \\
\hline - Lung ultrasound & - Incubation & $\begin{array}{l}\text { - Hospital surge capacity } \\
\text { planning }\end{array}$ & Governance $(n=6)$ & Others $(n=17)$ \\
\hline Clinical treatments $(n=454)$ & Public health burden $(\mathrm{n}=8)$ & Others $(n=5)$ & Others $(n=6)$ & \\
\hline - Hydroxychloroquine & - Seroprevalence & & & \\
\hline - Remdesivir & - Mortality & & & \\
\hline - Tocilizumab & $\begin{array}{l}\text { Prevention and control } \\
\text { measures }(n=109)\end{array}$ & & & \\
\hline - Cellar therapy & - Face masks & & & \\
\hline $\begin{array}{l}\text { - Traditional Chinese } \\
\text { medicine }\end{array}$ & - Hand washing & & & \\
\hline Clinical trials $(n=15)$ & - Social distancing & & & \\
\hline - Vaccines & Living habits $(\mathrm{n}=28)$ & & & \\
\hline - Drugs & - Smoking & & & \\
\hline Clinical outcomes $(n=123)$ & - Physical activity & & & \\
\hline $\begin{array}{l}\text { - Discharge rate, and fatality } \\
\text { rate }\end{array}$ & Environment $(n=7)$ & & & \\
\hline - Recurrence & Others $(\mathrm{n}=38)$ & & & \\
\hline \multicolumn{5}{|l|}{ - Critical Complications } \\
\hline \multicolumn{5}{|l|}{$\begin{array}{l}\text { Clinical risk prediction } \\
\text { models }(\mathrm{n}=15)\end{array}$} \\
\hline \multicolumn{5}{|l|}{$\begin{array}{l}\text { - Model development and } \\
\text { validation }\end{array}$} \\
\hline \multicolumn{5}{|l|}{$\begin{array}{l}\text { COVID-19 and } \\
\text { comorbidities }(n=480)\end{array}$} \\
\hline \multicolumn{5}{|l|}{ - Liver and kidney Injury } \\
\hline \multicolumn{5}{|l|}{ - Diabetes mellitus } \\
\hline \multicolumn{5}{|l|}{ - Cardiovascular diseases } \\
\hline \multicolumn{5}{|l|}{ - Mental health } \\
\hline Others $(n=149)$ & & & & \\
\hline
\end{tabular}


Clinical management of COVID-19 and pandemic-related health issues, a total of 1755 reviews were divided into seven subgroups: Clinical features $(n=372)$; Clinical tests $(n=147)$; Clinical treatments $(n=454)$; Clinical trials $(n=15)$; Clinical outcomes $(n=123)$; Clinical risk prediction models $(n=15)$; and COVID-19 and comorbidities $(n=480)$.

Public-health measures, a total of 342 reviews were divided into six subgroups: Infection $(\mathrm{n}=37)$; Transmission ( $\mathrm{n}=115)$; Public health burden $(\mathrm{n}=8)$; Prevention and control measures $(\mathrm{n}=109)$; Living habits $(\mathrm{n}=28)$; Environmental impact $(n=7)$.

Health-system arrangements, a total of 85 reviews were divided into two subgroups: Health care resource arrangement $(n=38)$; Clinical department arrangement $(n=42)$.
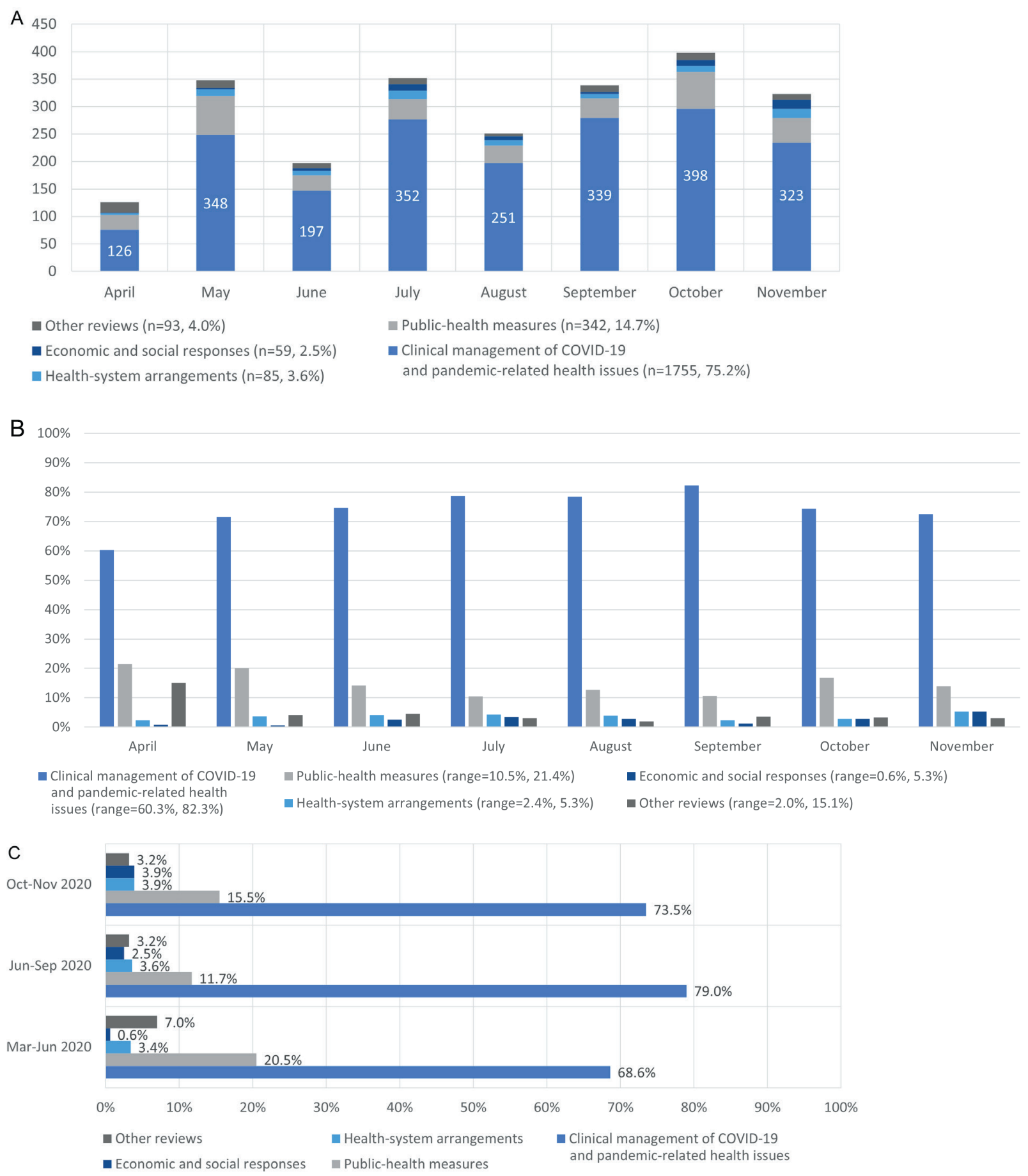

Figure 2. Number of reviews and distribution of review topics of the UNCOVER registry over time Panel A. Number of reviews entered in UNCOVER registry by the month of entry. Panel B. Proportion of review topics entered in the UNCOVER registry by the month of entry. Panel C. Proportion of review topics entered in the UNCOVER registry by the three time periods. 


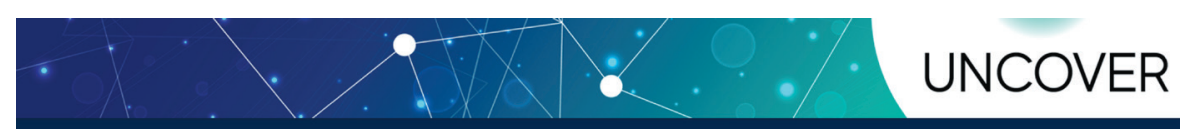

Usher Institute

UNCOVER (USHER NETWORK FOR COVID-19 EVIDENCE REVIEWS)
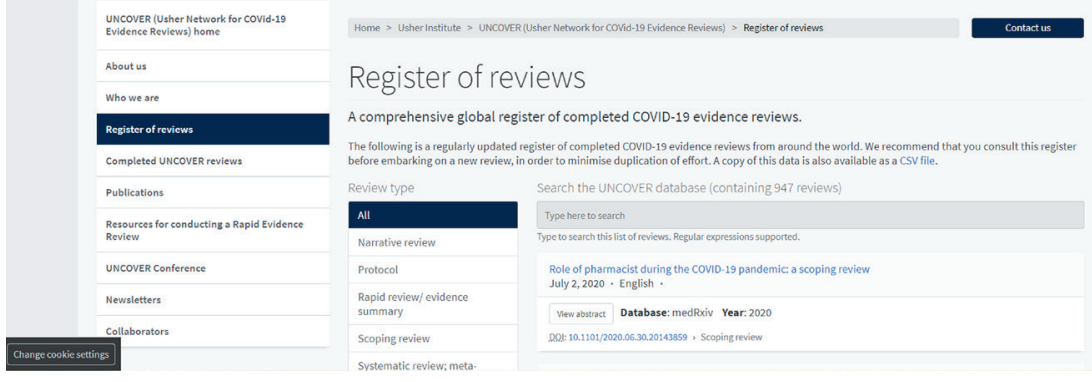

Photo: Register of reviews from UNCOVER team, the University of Edinburgh (from the author's own collection, used with permission).

ics has changed over time. Figure 2, Panel B, shows that the proportion of reviews on clinical management of COVID-19 and pandemic-related health issues increased from April to September (from 60.3\% to 82.3\%) but the proportion has been steadily declining since September to $74.4 \%$ and $72.4 \%$ for October and November respectively. In contrast, the proportion of reviews on public health measures decreased from May to September except for August (from 21.4\% to 10.5\%) and the proportion was higher in October and November (16.8\% and 13.9\% respectively). For the other three topics, the trend is fluctuating. We further categorized the pandemic into three time periods: 1) before June 2020, where the main contributors were Western Pacific, Americas and Europe but the case incidence was kept in relatively low levels; 2) June-September 2020, where the number of new cases continued to increase and the main contributors were Americas and South-East Asia;

\section{The research topics of COVID-19 related} reviews concentrated on clinical features, tests, treatment and outcomes, COVID-19 comorbidities, and the transmission, prevention and control of COVID-19. and 3) October 2020 to now, where the number of cases increased significantly driven by the second outbreak in Americas and Europe. From Figure 2, Panel C, the highest proportion of reviews on clinical management of COVID-19 and pandemic-related health issues was in June to September while the proportion of reviews on public health measures was relatively high in periods before June and after September. The proportion of reviews on economic and social responses has been increasing, but they still account for a small proportion.

In summary, a total of 2334 COVID-19 evidence-based reviews have been indexed in UNCOVER registry, more than half of the reviews included were from PubMed, and over two-thirds of the included reviews were systematic reviews and meta-analyses. The research topics concentrated on clinical features, tests, treatment and outcomes, COVID-19 comorbidities, and the transmission, prevention and control of COVID-19. Although we have seen an increasing trend for reviews on economic and social responses across the three time periods, the total number remains very low and not in line with its importance.

The registry offers the opportunity to explore the aforementioned topics using state of the art methodologies in evidence-based research (such as umbrella reviews with evidence synthesis and assessment of the risk of bias) [8-12]. This will provide policymakers, clinicians and researchers a clear understanding of broad topic areas in relation to COVID-19.

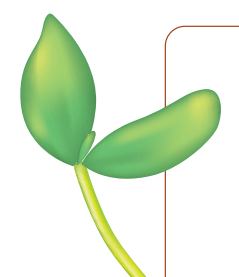

Acknowledgements: UNCOVER registry authors would like to acknowledge Prof Harry Campbell, Dr Ruth McQuillan, Prof Harish Nair, Ms Emilie McSwiggan, and LTW Website and Communications team.

Funding: The UNCOVER network is a Data-Driven Innovation, Welcome Trust's Institutional Strategic Support Fund (ISSF3), and Principal's Teaching Award Scheme supported project. ET is supported by a CRUK Career Development Fellowship (C31250/A22804). XZ is supported by The Darwin Trust of Edinburgh.

Authorship contributions: XZ, WX wrote the manuscript with input from all co-authors. All authors have read and approved the final manuscript as submitted.

Competing interests: The authors completed the ICMJE Unified Competing Interest form (available upon request from the corresponding author), and declare no conflicts of interest 
1 World Health Organization. Coronavirus disease (COVID-2019) situation reports. 2020. Available on: https://www.who.int/ publications/m/item/weekly-epidemiological-update---14-december-2020. Accessed: 14 December 2020.

2 World Health Organization. A coordinated global research map: 2019 novel coronavirus. Available on: https://www.who.int/ publications/m/item/a-coordinated-global-research-roadmap. Accessed: 28 November 2020.

$3 \mathrm{Xu}$ W, Zhang X, He Y, Dozier M, Owers B, Li X, et al. UNCOVER registry: A searchable online catalogue for COVID-19 evidence reviews. J Glob Health. 2020;10:020101. Medline:33110500 doi:10.7189/jogh.10.020101

4 UNCOVER (USHER NETWORK FOR COVID-19 EVIDENCE REVIEWS). UNCOVER Register. 2020. Available on: https:// www.edweb.ed.ac.uk/usher/uncover/register-of-reviews. Accessed: 28 November 2020.

5 National collaborating centre for methods and tools. COVID-19 Rapid Evidence Reviews. 2020. Available on: https://www.nccmt.ca/covid-19/covid-19-evidence-reviews. Accessed: 28 November 2020.

6 The Centre for Evidence-Based Medicine. COVID-19 Rapid Evidence Reviews. 2020. Available on: https://www.cebm.net/oxford-covid-19-evidence-service/. Accessed: 28 November 2020.

7 McMaster University. COVID-END. Available: https://www.mcmasterforum.org/networks/covid-end/resources-to-supportdecision-makers/taxonomy-of-decisions/context. Accessed: 28 November 2020.

8 Theodoratou E, Tzoulaki I, Zgaga L, Ioannidis JP. Vitamin D and multiple health outcomes: umbrella review of systematic reviews and meta-analyses of observational studies and randomised trials. BMJ. 2014;348:g2035. Medline:24690624 doi:10.1136/bmj.g2035

9 Li X, Meng X, Timofeeva M, Tzoulaki I, Tsilidis KK, Ioannidis JP, et al. Serum uric acid levels and multiple health outcomes: umbrella review of evidence from observational studies, randomised controlled trials, and Mendelian randomisation studies. BMJ. 2017;357:j2376. Medline:28592419 doi:10.1136/bmj.j2376

10 He Y, Li X, Gasevic D, Brunt E, McLachlan F, Millenson M, et al. Statins and Multiple Noncardiovascular Outcomes: Umbrella Review of Meta-analyses of Observational Studies and Randomized Controlled Trials. Ann Intern Med. 2018;169:543-53. Medline:30304368 doi:10.7326/M18-0808

11 Zhang X, Gill D, He Y, Yang T, Li X, Monori G, et al. Non-genetic biomarkers and colorectal cancer risk: Umbrella review and evidence triangulation. Cancer Med. 2020;9:4823-35. Medline:32400092 doi:10.1002/cam4.3051

12 Xu W, He Y, Wang Y, Li X, Young J, Ioannidis JPA, et al. Risk factors and risk prediction models for colorectal cancer metastasis and recurrence: an umbrella review of systematic reviews and meta-analyses of observational studies. BMC Med. 2020;18:172. Medline:32586325 doi:10.1186/s12916-020-01618-6

\section{Correspondence to:}

Prof Evropi Theodoratou

Centre for Global Health

Usher Institute

University of Edinburgh

Old Medical School, Teviot Place

Edinburgh EH8 9AG

UK

e.theodoratou@ed.ac.uk 